Case Report

Relato de Caso

Andréa Gomes de Oliveira ${ }^{1}$ Márcia Monteiro Pinho²

Keywords

Brachial plexus neuritis Vocal cord paralysis Voice

Dysphonia Quality of life

Descritores

Neurite do plexo braquial Paralisia das pregas vocais Voz Disfonia Qualidade de vida
Correspondence address: Andréa Gomes de Oliveira Rua Magno Martins, 128, apto 121, Freguesia, Ilha do Governador, Rio de Janeiro (RJ), Brazil, CEP: 21911-430.

E-mail: agoaoliveira@gmail.com

Received: $12 / 26 / 2012$

\section{Extended Neuralgic Amyotrophy Syndrome: voice therapy in one case of vocal fold paralysis}

\section{Amiotrofia Nevrálgica Estendida: fonoterapia em um caso de paralisia de prega vocal}

\begin{abstract}
Neuralgic Amyotrophy (NA) is a rare disturb of the peripheral nervous system that can include extreme pain, multifocal paresis and atrophy of the muscles of the upper limbs. When the nerves located outside of the brachial plexus are involved, the term Neuralgic Amyotrophy Extended (ANE) is used. Diagnosis of NA is clinical and has a series of inclusion and compatibility criteria established by the European CMT Consortium. On this study the clinical history, multidimensional vocal assessment data and the vocal techniques used in five-weeks voice therapy for one patient, professional voice, with ANE are presented. In this case, sudden and recurrent paralysis of his right vocal fold was the only manifestation of the disease. At the end of the fifth week the patient's voice was normal, the spoken and sung vocal ranges were same as before the current episode of ANE and scores of his vocal self-assessment were appropriate.
\end{abstract}

\section{RESUMO}

A Amiotrofia Nevrálgica (AN) é um distúrbio raro do sistema nervoso periférico que pode incluir dor extrema, paresia multifocal e atrofia dos músculos dos membros superiores. Quando há o envolvimento de nervos localizados fora do plexo braquial, o termo Amiotrofia Nevrálgica Estendida (ANE) é utilizado. O diagnóstico da AN é clínico e possui uma série de critérios de inclusão, bem como critérios de compatibilidade estabelecidos pelo European CMT Consortium. Neste estudo são apresentados a história clínica, os dados da avaliação vocal multidimensional e as técnicas vocais utilizadas na terapia vocal de cinco semanas de um paciente, profissional da voz, com ANE. A paralisia súbita e recorrente da prega vocal direita foi a única manifestação da doença. Ao término da quinta semana, a voz do paciente estava adaptada, as extensões de voz falada e cantada eram as mesmas de antes da lesão e os escores de sua autoavaliação vocal estavam adequados.

Study carried out at the Otorhinolaryngology, 2nd Infirmary of Santa Casa de Misericórdia of Rio de Janeiro Rio de Janeiro (RJ), Brazil.

(1) Universidade Federal Fluminense - Rio de Janeiro (RJ), Brazil.

(2) Santa Casa de Misericórdia of Rio de Janeiro - Rio de Janeiro (RJ), Brazil.

Conflict of interests: nothing to declare. 


\section{INTRODUCTION}

The neuralgic amyotrophy (NA), brachial plexus neuritis, or Parsonage-Turner syndrome is a disorder of the peripheral nervous system (PNS) that may include episodes of extreme pain as one of its initial symptoms, sudden onset of multifocal paresis, and atrophy of the muscles of the upper limbs. Its recovery is slow and it takes months to years ${ }^{(1)}$.

The NA may be either hereditary or idiopathic. In the hereditary form, which is about 10 times less common, 55\% of the affected families present specific mutation or duplication of the septin 9 gene (SEPT9), located on chromosome $17 \mathrm{q} 25.3^{(1)}$. Besides genetic predisposition, the disease may be due to a susceptibility to the mechanical injury of the brachial plexus (for disruption of the blood-nerve barrier), an immune or autoimmune trigger ${ }^{(2)}$. Associations with different immunological events, such as infectious processes, have been reported ${ }^{(1)}$. The precise pathophysiological mechanisms are still not clear and preventive measures are not available ${ }^{(2)}$.

The upper trunk of the brachial plexus, formed by the ventral branches of the fifth and sixth cervical nerves (C5-C6), is the most commonly involved one. However, any part thereof, as well as other nerves, may be affected ${ }^{(1)}$. When there is involvement of nerves located outside the brachial plexus, the term extended neuralgic amyotrophy (ENA) is used ${ }^{(3)}$. Usually, this occurs in $17 \%$ of the patients with idiopathic NA and in $56 \%$ of those bearers of the inherited form ${ }^{(2)}$. In these, the lumbosacral plexus, the phrenic and/or laryngeal nerves are affected and, occasionally, the hypoglossal, facial, or intercostal nerves ${ }^{(2,4)}$.

The diagnosis of NA is clinical, and it has a number of inclusion criteria, as well as compatibility criteria established by the European CMT Consortium ${ }^{(5)}$. The incidence of NA is of 2-3 cases per 100,000 individuals per year in general population. However, considering diagnosis errors, the actual incidence may be of 20-30 cases per 100,000 individuals ${ }^{(2)}$.

Regarding the existing treatments, there is the use of pain killers and steroids in cases of pain and inflammation episodes. The need for rehabilitation in the long term, however, is recent ${ }^{(6)}$.

As in other disorders of the PNS, the recovery of the nerve affected in the NA depends on the number of remaining axons. These may promote collateral reinnervation, a process that may take several months to restore full muscle control, but with a decrease in resistance ${ }^{(1)}$.

In this study the findings of a multidimensional vocal assessment, before and after 5 weeks of voice therapy of a patient with sudden and recurrent paralysis of the right vocal fold and diagnosed with ENA, are presented. This study was carried out in accordance with the recommended ethical principles applicable to research on humans. The patient read and signed the informed consent form.

\section{CASE PRESENTATION}

A male individual (24 years of age, musician, and teacher of stringed instruments), complaining of hoarseness and weak voice for three-and-a-half months, sought our team for both otorhinolaryngological and speech-language pathology and audiology evaluation. According to him, the initial signs occurred suddenly. The patient was in a concert hall giving a presentation and talking occasionally to other musicians when his voice suddenly became hoarse. Before that, he had felt a "light throbbing on the neck, to the right" in the morning, along with a mild sore throat, without voice alterations. As, in the previous week, he had used levofloxacin for an upper respiratory tract infection (URTI), he then sought for otorhinolaryngological care. In his videolaryngoscopy, performed before the sudden onset of the dysphonia, normal mobility of both vocal folds and asymmetric position of arytenoid cartilage in abduction were observed.

In the first days after the onset of the dysphonia, the patient sought several otorhinolaryngologists, being subjected to four sessions of videolaryngoscopy. The diagnoses, mostly, were of vocal fold paralysis to the right side, in paramedian position, of idiopathic origin, and the patient was instructed to seek a neurologist. In the evaluation made by the first professional sought, the condition was described as associated with gastroesophageal reflux disease (GERD). Such association was made after diffuse hyperemia and mild pangastritis were detected by the endoscopy requested, and the patient used corticosteroids and a proton pump inhibitor. Another professional referred him to the neurology service of a university hospital and also advised him to seek for speech-language pathology and audiology care services.

The patient reported a single vocal antecedent, also hoarseness due to paralysis of the right vocal fold 5 years before, associated, at the time, to GERD, as well as other neurological antecedent, of hypertrophy of the trapezius muscle, 9 years before. Both occurred suddenly, and the recovery was made after a few months of vocal and physical therapy, respectively.

Before being evaluated by our team, the patient enlisted himself in a voice therapy program in another hospital, where he remained for approximately 3 months. That time, according to him, the complaint was hoarse and weak voice and vocal production a little better with higher pitched voice, which he started using. The patient used effort techniques, fricative sounds, and vibrant sounds with scales and neck movements. These were conducted 2-3 times a day during the program without any improvement in his voice quality. During the time in which the patient was in therapy, he reduced his workload to $10 \%$ and restricted communication to family members only.

In the same period, the neurological assessment at the university hospital indicated had begun. At the time he looked for our team, the patient had already undergone CT scans of the skull, neck, chest, and sinuses, as well as MRIs of the skull and cervical spine, but no evidence of injury or tumor had been found. The patient underwent an electromyography of the trapezius muscle, whose result was also in accordance with the standards of normality. The neurological diagnosis of ENA was made based on the recurrence of episodes of sudden onset of motor issues of neurological origin, without the presence of tumors or triggering injuries; long interval, lasting years between episodes; recurrence of involvement of the right vocal fold; presence of URTI as a possible precipitating factor of the current episode; and from the compatibility criterion, according to which 5\% of the cases have no pain during the episode ${ }^{(5)}$. 
Otorhinolaryngological and speech-language pathology and audiology assessment before and after vocal therapy

The patient underwent an otorhinolaryngological evaluation by our team 3 months and 7 days after the diagnosis of normal vocal fold mobility and asymmetric arytenoid cartilage abduction position, day on which, coincidentally, a sudden onset of dysphagia occurred. The evaluation included performing indirect laryngoscopy with rigid optic fibers.

The speech-language pathology and audiology evaluation was performed 20 days after the otorhinolaryngological evaluation and again after 5 weeks of voice therapy, and it included the perceptual auditory and voice acoustic analysis as well as a vocal self-assessment.

\section{Procedures}

The laryngoscopy was performed during the otorhinolaryngological evaluation with the ECLERIS strobe equipment, rigid optic of $70^{\circ}$.

For the perceptual and acoustic analysis of the speech-language pathology and audiology evaluation, the voice samples were captured and stored in the VoxMetria software (CTS Informática), with sampling frequency of $44,100 \mathrm{~Hz}$. The recording was done in a quiet room (with a noise level of $50 \mathrm{~dB}$ ), with a headset microphone, mono-sound, unidirectional, with flat response curve and noise neutralizer (Earset HX79).

In the acoustic analysis, the sample used was the vowel /E/ sustained in comfortable pitch and loudness. From this, we extracted the fundamental frequency $\left(F_{0}\right)$, maximum phonation time (MPT), considering the longest three samples obtained, jitter (period perturbation quotient, PPQ), shimmer (extent perturbation quotient, EPQ), and phonatory deviation diagram (PDD). For their irregular features, the beginning and end of the emissions were excluded for the extraction of the $F_{0}$, jitter, shimmer, and PDD.

The PDD is a quantitative method to evaluate the correctness and the sound of the beep. On the horizontal axis, there are three measures of the regularity of the signal (jitter, shimmer, and the waveform-matching coefficient) and on the vertical axis, the measure of noise of the acoustic signal (glottal noise energy, GNE). The PDD differentiates normal voices from diverted ones. The normal voices are located within the area of normality, and most diverted ones, outside that area ${ }^{(7)}$.

For the perceptive hearing analysis, we used samples of the vowel /a/ sustained, chained, and spontaneous speech in a usual manner for the evaluation of the parameters: loudness, pitch and emission stability, and classification according to the GRBAS scale ${ }^{(8)}$, the degree of identification of dysphonia, according to four independent factors. In this, the $G$ represents the overall grade, $\mathrm{R}$ the roughness, $\mathrm{B}$ the breathiness, $\mathrm{A}$ the asteny, and $\mathrm{S}$ the strain.

In the vocal self-assessment of the patient, we used the full version of the Voice Handicap Index (VHI) protocol, validated in Brazil in 2009 by Behlau et al. ${ }^{(9)}$ and the Voice-Related Quality of Life (VR-QOL) protocol, validated in Brazil by Gasparini and Behlau $^{(10)}$ in the same year.
The VHI is a valid and reliable vocal disadvantage inventory for patients with a wide range of voice disorders. It has three content domains - functional, organic, and emotional and contains 30 items, 10 for each of them. Each item can be answered using a Likert scale (from 0 , never, to 4 , always) ${ }^{(9)}$.

From the simple sum of the values, the total organic, functional, and emotional scores are obtained. The total score may range from 0 to 120 and the remaining ones from 0 to 40 . The higher questionnaire scores indicate greater severity of the disorder, being defined cutoff values that facilitate the assessment of the results of the voice therapy. The cutoff value of VHI for the total score is equal to 19 , for the organic domain 10.5 , for the functional domain 7.5, and for the emotional domain 3.0.

The VR-QOL is an instrument developed to assess the impact of a voice disorder in daily life, whose validity, reliability, and responsiveness have already been shown. Furthermore, it is an instrument that has been widely used. It contains ten items and two domains, of physical and socioemotional functioning, being six for the first and four for the second. Each item may be answered according to a Likert scale (from 1, not a problem, to 5 , a great problem) ${ }^{(10)}$.

From the simple sum of the values, the raw scores are obtained. These are inserted into algorithms for the calculation of the total scores, the domain of physical functioning, and socioemotional score. Higher scores indicate better quality of life related to voice. The maximum score is 100 and the minimum is 0 , both for a particular domain and for the total score. The cutoff value for the total score equals 91.25 , for the physical functioning score it is 89.60 , and for the socioemotional score it is 90.65 .

\section{Pre-therapy assessment data}

The laryngoscopy showed immobility of the right hemilarynx, paralyzed right vocal fold in median position, and slightly arcuate edge; medialization of the left vestibular fold and left vocal fold with preserved mobility and straight edge. Under natural strobe light emission, glottal closure was complete, but with intense aperiodicity. In falsetto, the mucosal wave was present only to the left, with extensive anterior-posterior triangular gap. After the evaluation, the patient was referred for speechlanguage pathology and audiology assessment and therapy.

In the perceptual auditory evaluation of voice quality, the patient had a hoarse voice, reduced loudness, higher pitch, with some falsetto stretches and frequency cracks. According to the GRBAS, the values obtained before treatment were the following: $\mathrm{G}=3, \mathrm{R}=3, \mathrm{~B}=3, \mathrm{~A}=0$, and $\mathrm{S}=1$.

In the acoustic assessment, with the sustained vowel $/ \mathrm{a} /$, the average $F_{0}$ obtained was $185 \mathrm{~Hz}$, high and inappropriate for men; the MPT was reduced in about $5 \mathrm{~s}$; and jitter and shimmer values were high, above the expected values (Table 1). In PDD, the distribution of the voice sample was outside the normality area in the graph, in the upper right quadrant (Figure 1, file 8). The signals obtained from the acoustic analysis, aperiodic, with noise and instability, were consistent with the perceptual evaluation. 
In the vocal self-assessment with the VHI, the scores obtained were the following: total score $=98$, emotional domain $=28$, functional domain $=37$, and organic domain $=33$; these expressed maximum voice disadvantage. With the VR-QOL, the scores were the following: total score $=5$, socioemotional $=0$, and physical functioning $=8.34$; they indicated quality of life and bad voice. The vocal self-assessment indicated that the voice alteration causes disadvantage and negative impact of the voice on the quality of life of the patient.

After the evaluation, the patient was instructed to use his voice in a natural way, even if its hearing characteristics were worse.

\section{Vocal therapy}

Vocal therapy was administered in weekly sessions with duration of 1 hour each. In the first session, the techniques used were laryngeal massage ${ }^{(11)}$, the yawn-sigh technique ${ }^{(12)}$, and inspiratory phonation ${ }^{(13)}$ associated with emissions in modal register, in a natural way. The patient was instructed to perform

Table 1. Acoustic measures in pre- and post-voice therapy

\begin{tabular}{lcc}
\hline Acoustic measures & Pre-therapy & Post-therapy \\
\hline Mean $F_{0}(\mathrm{~Hz})$ & 185.00 & 137.69 \\
MPT (seg) & 5 & 14 \\
Jitter (PPQ) & 5.49 & 0.06 \\
Shimmer (EPQ) & 25.97 & 4.60 \\
\hline
\end{tabular}

Caption: $\mathrm{MPT}$ = maximum phonation time; $\mathrm{PPQ}=$ period perturbation quotient; $E P Q=$ extent perturbation quotient them five times a day. The goals were the reduction of the unilateral median constriction, of the paralytic falsetto, and of the inappropriate compensatory adjustments, so that the work vocal competence, without excessive effort, would be initiated.

In the second session, the patient presented adequate pitch for sustained emission, a decrease in frequency cracks in spontaneous speech, and a slight increase in loudness, all positive answers to the techniques introduced in the first session of therapy. The techniques of prolonged $/ \mathrm{b} / /^{(14)}$ and emission issued with hand over the mouth, one of the exercises of semi-occluded vocal tract ${ }^{(15)}$, were added. They were aimed at reducing the unilateral median compression and reestablishing the neural function of the right vocal fold. The same frequency of application was maintained until the end of the third week, considering the need to stabilize the results for the return of the patient to his activities as a professional of the voice.

In the third week, the patient had his pitch reestablished, normal and stable voice in spontaneous speech, but with limited vocal range. Therefore, we added the techniques of emission in MPT, at different frequencies, aiming at adequating the glottal closure and improving phonatory stability ${ }^{(15)}$; and the technique of vibrant sounds associated with rising musical scales (between C3 and G3) and with head movements to both sides, in staccato and legato ${ }^{(15)}$.

In the fourth week, the patient showed improvement in his spoken and sung vocal range and restarted teaching music six hours a day. The techniques of basal sound, nasal sounds, and emission in MFT were included. A sequence of vocal warmup and cool-down exercises was prepared, with the use of
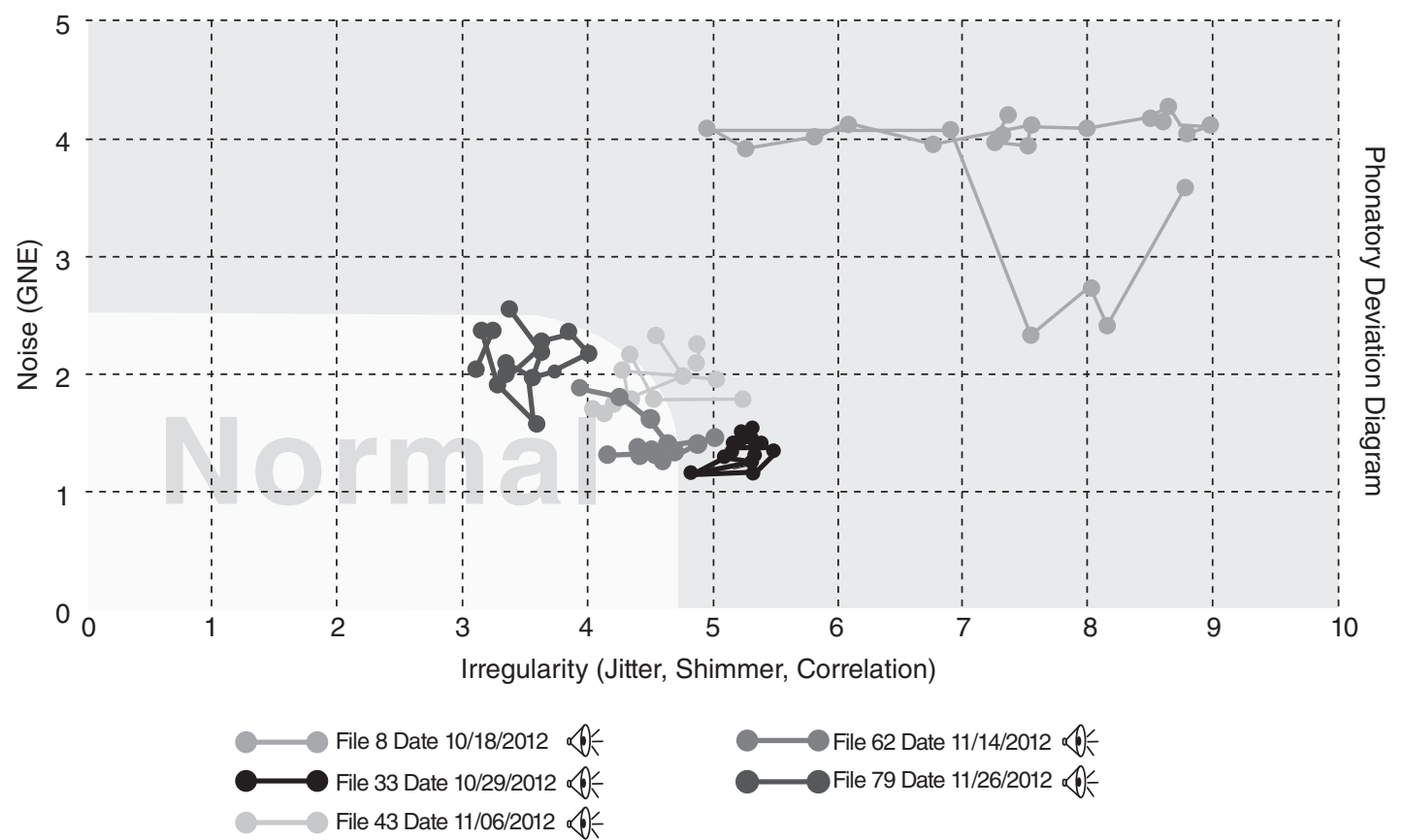

Figure 1. Phonatory deviation diagram before, during, and after 5 weeks of voice therapy. File 8, pre-therapy chart, located in the right upper quadrant, outside normality range; file 33, during therapeutical process, located in the lower right quadrant, with reduction of noise components and irregularity; files 43 and 62, located in the lower left quadrant, in transition toward normality area; file 79, after 5 weeks of therapy, located in the area of normality 
certain techniques learned, to work resistance concerning vocal demands. The other exercises were kept for home.

In the fifth assessment, held after 15 days, the patient had his extension of spoken and sung voice reestablished. This week, he reported having returned to his teaching of 8 hours a day, with a few breaks for rest. The patient was instructed to continue the vocal warm-up and cool-down exercises. In the sequence of the warm-up, the technique of vibrating sounds was also associated to songs, to improve the extent of the singing voice.

\section{Post-therapy vocal assessment data}

According to the perceptual auditory assessment of the voice's post-therapy quality, the values obtained with the GRBAS were the following: $\mathrm{G}=0, \mathrm{R}=0, \mathrm{~B}=0, \mathrm{~A}=0$, and $\mathrm{S}=0$, which expresses that the patient's voice came to be perceived as normal or adapted. Both loudness and pitch were also considered to be adequate.

After the treatment, the assessed values for all acoustic parameters were in accordance with normality. The average $F_{0}$ was $137.69 \mathrm{~Hz}$, suitable for men and for the function performed, with the MPT, jitter, and shimmer values in agreement with normality (Table 1). The PDD, which was in the right upper quadrant during the initial assessment, with great noise and irregularity component, gradually approached the area of normality (Figure 1, files 33, 43, and 62) until finally it was settled in this fifth week of therapy (Figure 1, file 79).

The scores obtained with VHI after the therapy (total score $=5$, emotional domain $=2$, functional domain $=1$, and organic domain $=2$ ) express a minimal disadvantage expected for people without vocal complaints. Scores obtained with the VR-QOL were the following: total score $=95.00$, socioemotional $=100.00$, and physical functioning $=91.67$, indicating good quality of life and excellent voice.

The post-therapy laryngoscopy showed a larynx with preserved mobility. There was a slight decrease in the extent of the right vocal fold abduction when compared to the left one. Under strobe light, a complete glottal closure, periodic glottal cycles, mucosal wave and regular vibration amplitude, amplitude symmetry, and discrete phase asymmetry were observed (Figure 2).

\section{DISCUSSION}

In the voice therapy of a patient with vocal fold paralysis, the selection of the most appropriate vocal techniques and the performing of their therapeutic proofs are some of the first steps to be followed by the speech-language pathologist.

When the presented patient began being monitored, he had been in voice therapy for 3 months in another hospital, but without using any techniques for reduction of the unilateral median constriction, elimination of paralytic falsetto, reestablishment of the neural function of the right vocal fold, or compensation of the left vocal fold. During this period, his vocal quality remained unchanged: hoarse-breathy in moderate degree with elevated pitch, in falsetto register, in a compensatory way and

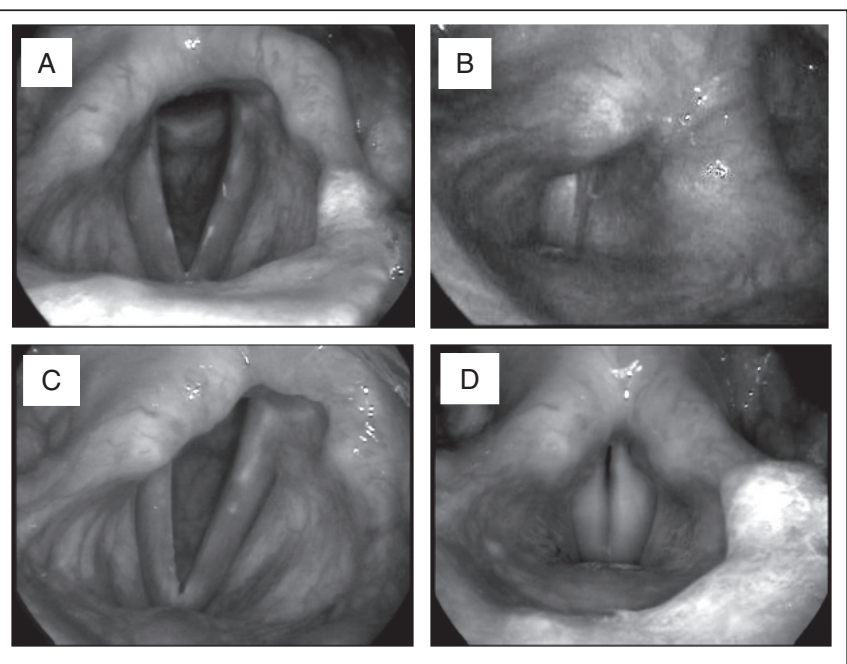

Figure 2. (A, B) Laryngeal images before voice therapy. Paralyzed right vocal fold in median position, with visible anteromedial displacement of the ipsilateral arytenoid cartilage and medialized left vestibular fold. (C, D) After therapy, vocal fold with recovered mobility, only with asymmetry of the arytenoid cartilage position, visible during glottal abduction

reduced loudness. Given the lack of implementation of appropriate vocal techniques, such parameters were maintained or even exacerbated, according to laryngeal assessment performed afterwards (Figure 2b).

Regarding the diagnosis of ENA, sudden occurrence or recurrence of muscle impairment in one or more regions, innervated or not by the plexus nerve, without any pathognomonic changes in the imaging tests, is a sign that may be reported by patients ${ }^{(5)}$. Moreover, lack of recent clinical history of intubation, trauma, thyroidectomy, vascular and metabolic diseases, and acute inflammatory conditions ${ }^{(15)}$ allows the differential diagnosis. In the present case, despite the detailed report made by the patient and his family, the patient's condition was initially attributed to GERD, as in the episode previous to the paralysis of the right vocal fold presented by him. In this sense, the neurological investigation should be prioritized by the team.

There are no studies in the literature showing the incidence of ENA with laryngeal paralysis. Among the existing cases, the most recent one was that of a patient in Spain, 65 years of age, female, with paralysis of the right vocal fold as the first manifestation of ENA ${ }^{(16)}$. After 8 weeks under expectant conduct, there was partial improvement of the dysphagia. After a year, her voice was nearly normal, by compensatory action of the left vocal ford and not by the reestablishment of the neural function of the right vocal fold. None of the cases described in literature have undergone voice therapy.

In this article, first documented in Brazil, the time for the vocal rehabilitation of patients occurred for only 5 weeks, when the patient would undergo speech-language pathology and audiology therapy and multidimensional pre- and post-therapy assessment. Despite the possibility of spontaneous recovery within a year, the expectant conduct in cases of recurrent paralysis of the laryngeal nerve is not 
recommended, since early speech-language pathology and audiology intervention may prevent negative compensations and achieve fast and satisfying results ${ }^{(17)}$.

In the voice therapy conducted, the main vocal techniques used were yawn-sigh ${ }^{(12)}$ and inspiratory phonation ${ }^{(13)}$, to eliminate the paralytic falsetto and to reduce the compensatory unilateral median constriction; prolonged $/ \mathrm{b} /{ }^{(14)}$ and emission issued with hand over the mouth ${ }^{(15)}$, aiming at the reestablishment of neural function of the right vocal fold of the patient. As described in the literature, cases of paralytic falsetto should be immediately treated, with the completion of intensive speech-language pathology and audiology therapy ${ }^{(16)}$. In the present case, the frequency of the exercises, five times a day, was adapted to the routine of the patient, who would wake up after 12 hours due to his engagements as a musician. It is possible that, in other cases, there is a need for a higher frequency of daily exercises.

The quickest and most efficient improvement, when compared to the case described in the literature, highlights the importance of speech-language pathology and audiology and otorhinolaryngological operations in cases of ENA, as well as in cases of paralysis of the inferior or recurrent laryngeal nerve. In cases of suspected ENA, referral for neurological research should be prioritized, as these may be the first professionals to be sought, as in this case. Furthermore, one should also consider the possibility of new sudden episodes, for which there are no preventive mechanisms described in the literature. Thus, the contact of the patient with the team may be useful for offering immediate support, since pre-episode signs and symptoms will be missing.

\section{FINAL COMMENTS}

The investigation and diagnosis of neurological patients with laryngeal paralysis of sudden origin, recurrent or not, in the absence of pathognomonic signs in additional scans are extremely important, because cases of ENA may be found.

ENA patients with vocal fold paralysis can have voice therapy as a great ally in their process of rehabilitation. The selection of proper vocal techniques, whose evidence have been presented in speech-language pathology and audiology literature, may be useful in reducing the recovery time (of months and years) in future cases.
*AGM and MP were responsible for data collection; MP collaborated with the tabulation and analysis of the data; $A G O$ was responsible for the project, the design of the study and overall direction of the stages of implementation and preparation of the manuscript.

\section{REFERENCES}

1. van Alfen N. Clinical and pathophysiological concepts of neuralgic amyotrophy. Nat Rev Neurol. 2011;7(6):315-22.

2. van Alfen N, van Engelen BG. The clinical spectrum of neuralgic amyotrophy in 246 cases. Brain. 2006;129(Pt 2):438-50.

3. Byrne E. Extended neuralgic amyotrophy syndrome. Aust N Z J Med. 1987;17(1):34-8.

4. England JD. The variations of neuralgic amyotrophy. Muscle Nerve. 1999;22(4):435-6.

5. van Alfen N, Hannibal MC, Chance PF, van Engelen BGM. Hereditary neuralgic amyotrophy. In: Pagon RA, Adam MP, Bird TD, Dolan CR, Fong CT, Stephens K, editors. GeneReviews ${ }^{\mathrm{TM}}$ [Internet]. Seattle (WA): University of Washington; 1993-2013.

6. van Alfen N, van der Werf SP, van Engelen BG. Long-term pain, fatigue, and impairment in neuralgic amyotrophy. Arch Phys Med Rehabil. 2009;90(3):435-9.

7. Madazio G, Leão S, Behlau M. The phonatory deviation diagram: a novel objective measurement of vocal function. Folia Phoniatr Logop. 2011;63(6):305-11

8. Hirano M. Clinical examination of voice. New York, NY: Springer; 1981.

9. Behlau M, Santos LMA, Oliveira G. Cross-cultural adaptation and validation of the voice handicap index into Brazilian Portuguese. J Voice. 2011;25(3):354-9.

10. Gasparini G, Behlau M. Quality of life: validation of the Brazilian version of the voice-related quality of life (V-RQOL) measure. J Voice. 2009;23(1):76-81.

11. Aronson AE. Clinical voice disorders: an interdisciplinary approach. New York, NY: Thieme; 1985.

12. Boone DR. Is your voice telling on you? San Diego, CA: Singular Publishing Group; 1991.

13. Powers WE, Holtz S, Ogura J. Contrast examination of the larynx and pharynx: inspiratory phonation. Am Journal Roentgenol. 1964;92:40-2.

14. Elliot N, Sundberg J, Gramming P. Physiological aspects of a vocal exercise. J Voice. 1997;11(2):171-7.

15. Behlau M, Madazio G, Feijó D, Azevedo R, Gielow I, Rehder MI Aperfeiçoamento vocal e tratamento fonoaudiológico das disfonias. In: Behlau M, organizadora. Voz: o livro do especialista - Vol. II. Rio de Janeiro: Revinter; 2005. p.409-564

16. Samarà L, Valls-Sole J, Caballero M. Dysphonia as an unusual debut of Parsonage-Turner syndrome. Head Neck. 2012;35(7):E229-30.

17. Behlau M, Madazio G, Azevedo R, Brasil O, Vilanova LC. Disfonias neurológicas. In: Behlau M (org.). Voz: o livro do especialista - Vol. II. Rio de Janeiro: Revinter; 2005. p.111-86. 